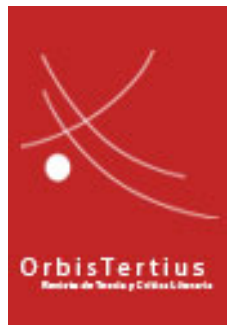

Orbis Tertius, vol. XXIII, nº 27, e074, junio 2018. ISSN 1851-7811

Universidad Nacional de La Plata

Facultad de Humanidades y Ciencias de la Educación

Centro de Estudios de Teoría y Crítica Literaria

\title{
La biógrafa cautelosa. Sobre La hermana menor. Un retrato de Silvina Ocampo, de Mariana Enríquez
}

\section{Patricio Fontana *}

* Universidad de Buenos Aires, Argentina.

Cita sugerida: Fontana, P. (2018). La biógrafa cautelosa. Sobre La hermana menor. Un retrato de Silvina Ocampo, de Mariana Enríquez. Orbis Tertius, 23 (27), e074. https://doi.org/10.24215/18517811e074 


\title{
La biógrafa cautelosa. Sobre La hermana menor. Un retrato de Silvina Ocampo, de Mariana Enríquez
}

\author{
Patricio Fontana \\ Universidad de Buenos Aires, Argentina
}

\section{ReSUMEN:}

En este artículo se propone una lectura del libro de Mariana Enríquez La hermana menor. Un retrato de Silvina Ocampo, publicado en Chile en 2014. Entre otras cosas, el análisis se focaliza en lo que se define como la figura de la biógrafa cautelosa; es decir, una biógrafa que, en la escritura de su texto, avanza con cautela, amedrentada. Esa cautela, ese amedrentamiento, se produce al menos por dos razones: por un lado, la imposibilidad de la biógrafa de acceder al archivo de Ocampo; por otro, el peso que sobre su escritura ejercen algunos postulados establecidos por ciertas entonaciones de la teoría literaria. En este sentido, el análisis se detiene especialmente en ciertos equívocos vinculados a la inscripción genérica del texto y, después, al modo como en él Enríquez da cuenta trabajosamente de la relación entre la vida y la obra de Silvina Ocampo.

Palabras clave: Silvina Ocampo - Mariana Enriquez-Biografía-Archivo .

\section{Abstract:}

This article proposes a reading of the book La hermana menor. Un retrato de Silvina Ocampo, by Mariana Enríquez (Chile, 2014). Among other things, the analysis focuses on what is defined as the figure of the a cautious biographer; i. e.,: a biographer who, in the writing of her text, advances warily, with caution, frightened. This caution, this intimidation, occurs foris due to at least two reasons: on one hand, the biographer's impossibility to access to Ocampo's archive; on the other, the weight carried by of certain postulates established by some intonations of literary theory. In this sense, the analysis especially emphasis delves into especially on certain ambiguities related to the generic inscription of the text, and on the way in which Enríquez can hardly accounts for the relation between Silvina Ocampo's life and work.

KeYwORDS: Silvina Ocampo - Mariana Enríquez-Biography - Archive .

En un artículo publicado hace casi veinticinco años titulado "Design and Truth in Biography", el biógrafo y por ese entonces profesor de la Universidad de Princeton Arnold Rampersad ${ }^{1}$ se refería a la capacidad de la biografía para superar contextos teóricos que, en apariencia, parecían no serle demasiado favorables. Allí, por ejemplo, al referirse al auge que por esos años tenían las posiciones críticas que predicaban la "desaparición del autor" [disappearance of the author] aseguraba que, desde su perspectiva, éstas no resultaban incompatibles con estudios históricos más profundos sobre el autor en cuestión. En este punto, Rampersad avanzaba aún más y afirmaba que la biografía lograba mantenerse en pie y aun prosperar en razón de ciertas esterilidades [sterilities] que parecían caracterizar las teorías literarias en boga por esos años. Cito a Rampersad:

Después de todo, el autor había desaparecido antes, cara a cara con el New Criticism, que fue como la mayoría de nosotros fue entrenada para leer literatura. Ahora el New Criticism, antes un gigante, yace a un lado, oxidándose en la gran zanja que corre junto a la autopista de la historia literaria. La biografía, sin embargo, no sólo sobrevivió al New Criticism sino que alcanzó nuevas alturas de reconocimiento y aceptación debido precisamente a las austeridades del New Criticism. Similarmente, debemos preguntarnos si la biografía está prosperando hoy día -y está prosperando- en razón de las esterilidades de los nuevos acercamientos a la teoría (1992: 5).

Rampersad, lamentablemente, no se detiene en su artículo en aquello que quizá habría resultado más interesante: la descripción de cuáles serían esas “austeridades” o "esterilidades” merced a las cuales el género o subgénero biografía de autor habría seguido prosperando en contextos teóricos que no parecían propiciarlo. De todos modos, podemos conjeturarlas o intuirlas: las teorías literarias a las que se refiere sumariamente 
Rampersad -estructuralismo, posestructuralismo, deconstrucción, semiótica, etcétera- harían del hecho literario algo inerte, exánime, desvitalizado. La biografía, por el contrario, con su insistencia en la relación entre vida y obra le devolvería al hecho literario al menos un poco de esa vitalidad de la que la teoría literaria la despojaría indefectiblemente. Por lo demás, y más allá de esa conjetura, lo cierto es que Rampersad opone a lo austero y a lo estéril de ciertas teorías literarias lo que deberíamos llamar, según entiendo, la exuberancia y la fertilidad de la biografía de autor.

Teniendo como punto de partida esas consideraciones de Rampersad para el ámbito de la academia norteamericana a comienzos de los años noventa, y más allá de que esa caracterización sea precisa o no, ¿qué podemos decir sobre el estatuto de la biografía de autor en la actualidad? Por lo pronto, en principio, pareciera ser que cierto regreso teórico al autor legitimaría la posibilidad de la escritura de textos de índole biográfica sin la necesidad de que aquel que encare esa tarea se sienta en la necesidad de dar mayores explicaciones, de comparecer, culposamente, ante el tribunal de la teoría. Vale decir, cierto retorno del autor, cierto nuevo interés por el problema de la autoría, legitimaría la posibilidad de la práctica biográfica. Pero, en este punto, es necesario aclarar que ese retorno no es ingenuo, inocente. $\mathrm{Al}$ respecto, en un esclarecedor trabajo del año 2006 que cierra un volumen de los Cabiers de LI.RI.CO consagrado a las "Figuras de autor" en el Río de la Plata, Julio Premat se ve en la necesidad de aclarar lo siguiente: “[...] el 'retorno del autor' y el 'retorno del sujeto' de los últimos años no es sólo un aggiornamiento revisionista de los setenta, sino un cambio que impone una redefinición del autor -es decir: estamos pensando al autor de manera diferente" (2006: 312). No me interesa detenerme ahora en las implicaciones de esa "manera diferente" a la que se refiere Premat. Lo que sí me interesa plantear, a modo de hipótesis tentativa de trabajo, es que la posibilidad de la escritura de una biografía de autor -sobre todo en lo que respecta a la relación vida-obra- está hoy cercada, intimidada, por ese retorno al autor que, al mismo tiempo, pareciera legitimarla. En otras palabras, la biografía de autor, a no ser que quiera pecar de ingenua, de anacrónica, deberá avanzar con cautela, con pies de plomo, con plena consciencia de esa "manera diferente" de pensar al autor que tiene lugar en la contemporaneidad.

Las consideraciones anteriores, y todo lo que acaso tienen de tentativo y de arbitrario, surgen de mi interés por proponer, en estas páginas, una lectura de un texto publicado en el año 2014 titulado La hermana menor. Un retrato de Silvina Ocampo de la narradora y periodista argentina Mariana Enríquez. El libro fue publicado en Chile por la Universidad Diego Portales en una colección denominada "Vidas Ajenas". La colección, según entiendo, toma su nombre del libro Vidas ajenas. Principia Biographica, de Leon Edel, el reconocido biógrafo de Henry James. Sin embargo, "Vidas Ajenas" no es una colección de biografías ortodoxas como las que Edel escribió y cuyos principios desglosa en aquel volumen de $1984,{ }^{2}$ sino de una que, al menos hasta el momento de la aparición de La hermana menor, había ofrecido a sus potenciales lectores textos biográficos y autobiográficos anómalos, heterodoxos, escritos, entre otros, por John Aubrey, Lytton Strachey, Gabriela Mistral u Oscar Wilde. Por ello, en este punto, la primera pregunta para hacerle a La hermana menor -o, al menos, la primera pregunta que yo quiero hacerle- es si se trata o no de una biografía.

$\mathrm{Al}$ respecto, el título, el texto y la contratapa eluden con vehemencia cualquier referencia al género: $L a$ hermana menor no sería una biografía sino, por el contrario, un retrato. Consecuentemente, la reseña que publicó el suplemento literario del diario Página/ 12 el 6 de julio de 2014 firmada por Ángel Berlanga, evitaba también cualquier alusión al género biográfico. Sin embargo, en una reseña publicada tres meses después en Babelia -el suplemento literario del diario español El País - la bajada anunciaba, sin mayores escrúpulos, que "una nueva biografía arroja luz sobre la figura de Silvina, brillante cuentista, amiga de Borges y esposa de Bioy Casares" y, en sintonía con esto, el reseñador -Ernesto Ayala-Dip- no titubeaba en referirse al libro de Enríquez como " $[\mathrm{u}] \mathrm{n}$ amplio retrato donde caben su biografía y la razón de su vida: la literatura, repartida entre novela, cuentos y poesía” (énfasis mío). Es decir, para Ayala-Dip La hermana menor sería algo más y no algo menos que -o algo diferente de- una biografía. Más recientemente, el libro de Enríquez mereció la atención de Walter Lezcano en un artículo que se publicó el 3 de agosto de 2016 en el suplemento "Ideas" del diario La Nación; un artículo que, al menos por su título - "De Silvina Ocampo a Osvaldo Lamborghini: 
las mejores biografías de escritores"- parecía, como el de Ayala-Dip, reconocer en él una biografía de escritor. No obstante, en el sector de la nota dedicado específicamente al libro de Enríquez, la propia autora parece y enfatizo: parece- aportar alguna precisión en cuanto al estatuto genérico de La hermana menor:

Con Leila Guerriero, que editó el libro, no lo planteamos como una biografía sino como un perfil biográfico. No teníamos pretensión de totalidad. Leo bastantes biografías; pero para escribir esta leí vidas de escritores y personajes más segmentadas, porque la idea era una mirada antes que nada.

Habría, pues, según la autora, dos elementos que alejarían su texto de lo que sería cabalmente una biografía: la no pretensión de totalidad y el hecho de aportar "una mirada antes que nada". Mi pregunta, entonces, es: ¿son esos elementos suficientes como para zanjar definitivamente el problema y establecer que La hermana menor no es una biografía? Y, de manera más general: ¿existe esa frontera que separa, por caso, la biografía de lo que Enríquez llama "perfil biográfico"? ${ }^{3}$ En un texto ya clásico sobre el género, Arnaldo Momigliano establece de manera sucinta que una biografía es, sencillamente, "Una relación de la vida de un hombre desde su nacimiento hasta su muerte [...]" (1986:22). La hermana menor cumple con ese requisito: en efecto, se nos narra la vida de Silvia Ocampo desde su nacimiento hasta su muerte. En cuanto a la pretensión de totalidad: ¿en qué totalidad está pensando Enríquez? ¿Cuánta totalidad es necesaria para que un texto deje de ser un "perfil biográfico" y pase a ser una biografía? El libro, de más de 200 páginas, recorre muchísimas facetas de la vida de Silvina Ocampo y la reacción de quien lo lee no es -o al menos no lo fue en mi caso- que en él falte demasiado por contar sobre esta vida. De hecho, en la misma nota, Enríquez declara que, de la vida de Ocampo, "[t] odo me interesó: su extravagancia, su literatura tan particular -escrita, encima, al lado de la de Borges, Bioy, Wilcock-, las peripecias de su vida privada, una vida que recorrió todo el siglo XX de la Argentina, sus contradicciones y sus secretos". Y, por último, ¿sólo los "perfiles biográficos" proponen una "mirada" sobre el biografiado? ¿Acaso no toda biografía es, indefectiblemente, una mirada - un punto de vista- sobre el biografiado?

A lo que apunto con todo lo anterior no es, en principio, al interés por resolver definitivamente a qué género pertenece La hermana menor, a decidir, de manera tajante, si es o no es una biografía de escritor. Antes bien, lo que sí me interesa son dos cuestiones: una más puntual referida a la relación de la autora con su texto y otra más general relacionada con los límites y las características del género en sí. En cuanto a la primera, razono que la insistencia en definir a La hermana menor como un "retrato" o como un "perfil biográfico" se debe menos a las certidumbres acerca de las diferencias, acaso inexistentes, entre el retrato y la biografía, que a cierta posición defensiva de la autora con respecto a su texto: a la voluntad de atajarse o guarecerse ante posibles críticas que le solicitaran más exhaustividad, más totalidad. En este sentido, me interesa ver en Enríquez a una biógrafa intimidada o amedrentada ante biografías como, por caso, el Rimbaud de Enid Starkie - de la que se confiesa admiradora-; una biógrafa que, previsoramente, se refugia en el sintagma "retrato biográfico" para así conjurar cualquier posible ataque a su texto por parte de los fanáticos de esas entonaciones monumentales y archivísticas de la biografía. El concepto de "retrato biográfico" se hallaría vinculado, entonces y en primer lugar, a una imposibilidad: la de poder acceder al archivo, en este caso, al que posee Ernesto Montequin, albacea de Silvina Ocampo.

En este sentido -y esta es la segunda cuestión a la que me referí anteriormente-, habría que pensar en el fuerte nudo entre biografía y archivo, un nudo que parece no poder desatarse: ¿este nudo siempre existió o fue tan fuerte? ¿Toda biografía debe presuponer, antes que nada, el acceso al archivo, el trabajo con el archivo? ¿El tener o no tener acceso al archivo sería lo que diferencia a la biografía de otros géneros que también ponen una vida en palabras? ¿No es posible, en la contemporaneidad, reivindicar una escritura biográfica que haga más énfasis en lo que François Dosse, en su ineludible libro sobre el género, denominó el "polo imaginativo del biógrafo"? ¿La biografía -ese arte vulnerable- sufre en la actualidad, y más que nunca, de cierto mal de archivo? $^{4}$ 
El libro, entonces, está construido a partir de una imposibilidad: la de acceder al archivo (y por consiguiente, de acercarse más a la biografiada). El de Enríquez no es el caso de muchos biógrafos que escriben contra las biografías ya existentes de sus biografiados (ese fue, por ejemplo, el caso de Charles Baudelaire, que cuando concibió su ensayo biográfico sobre Edgar Allan Poe escribió contra el texto biográfico que Rufus Griswold le había consagrado al autor de "El cuervo"). Enríquez, antes bien, escribe bajo la intimidante sombra de un libro por ahora inexistente, un libro-fantasma: la biografía monumental que Ernesto Montequin, o alguien designado por él, podría escribir. Al respecto, en un reportaje que le realizó Patricio Zunini, titulado sintomáticamente "Silvina en la bruma", Enríquez comenta:

Le pusimos [con Leila Guerriero] como subtítulo "un retrato de” porque el material necesario para escribir una biografía con más densidad lo tiene el albacea, Ernesto Montequin. Él fue muy generoso al contarme lo que tenía y permitirme entrevistarlo, pero no tuve acceso a los materiales. Supongo que los reserva para hacer una biografía que escribirá él o que decidirá él quién la escriba (Zunini 2014).

Y así, es esa imposibilidad del acceso al archivo la que lleva a la biógrafa a plantear que, antes que nada, su biografiada se le presenta como un misterio. ${ }^{5}$ De este modo, a poco de iniciado el libro, leemos:

Hermana de Victoria Ocampo, esposa de Adolfo Bioy Casares, amiga íntima de Jorge Luis Borges, una de las mujeres más ricas y extravagantes de la Argentina, una de las escritoras más extrañas de la literatura en español: todos esos títulos no la explican, no la definen, no sirven para entender su misterio (15).

El misterio -un término que se repite en el texto- será, desde entonces, el modo central como se presentará en La hermana menor a Silvina Ocampo. Enríquez, por lo tanto, preferirá casi siempre la duda a la certidumbre, la conjetura a la afirmación, las varias versiones a la versión definitiva. Así, lo esquivo del archivo tendrá su correlato en el carácter a menudo escurridizo, opaco e incluso fantasmático de la biografiada, en la imposibilidad de ofrecer al lector asertos definitivos sobre varios aspectos de esta vida. Esto ocurrirá con respecto a los motivos de su difícil relación con su hermana Victoria, con respecto al triángulo amoroso que conformaron Silvina, su sobrina Genca y Adolfo Bioy Casares o, por nombrar sólo un ejemplo más entre varios, con respecto a los detalles precisos de su vínculo con Alejandra Pizarnik. Así como su pertenencia genérica, considero que este modo no asertivo de presentar a Ocampo es producto de la biógrafa cautelosa o intimidada que se constituye en La hermana menor. Y a propósito de esto, habría que decir que menos que "una mirada" este retrato biográfico presenta una miríada de miradas sobre Silvina Ocampo; una miríada de miradas que ayuda a apuntalar la idea de misterio a la que acabo de referirme. Por esta razón, me interesa postular que lo mismo que asegura Enríquez sobre su biografiada -“[...] en definitiva, ella inventó su misterio para no tener que dar explicación"- podría afirmarse sobre su propia tarea como biógrafa: ella crea el misterio para no tener que dar explicación. ${ }^{6}$

En razón de lo anterior, considero que el capítulo 3, titulado "Donde las nubes son las montañas", puede leerse como una suerte de alegoría de esa posición obligadamente distanciada de Enríquez con respecto a Ocampo; vale decir: propongo leer ese capítulo como un testimonio de la imposibilidad de acceder o acercarse todo lo deseado a la biografiada (y así, el principal motivo por el cual ésta se transforma en un "misterio" para su biógrafa). En ese capítulo, Enríquez relata la visita que hizo a la localidad bonaerense de Pardo, ubicada a 35 kilómetros de la ciudad de Las Flores, donde aún se conserva una de las estancias de la familia Bioy Casares: Rincón Viejo (donde, entre otras cosas, Bioy y Ocampo vivieron antes de casarse). Enríquez cuenta que el pueblo es muy pequeño, que en 15 minutos se lo puede recorrer, que allí "se habla de ellos [de los Bioy] con respeto e interés, con la nostalgia de un paraíso perdido" (35). También cuenta que en la estación de tren hay un "pequeño museo Adolfo Bioy Casares", donde "Silvina Ocampo es una actriz secundaria"; en este orden de cosas, tanto en Pardo como en Las Flores Enríquez no puede recoger demasiados datos sobre Ocampo: allí "muchos recuerdan a los Bioy -al padre y al hijo- y pocos a Silvina" (39). En la misma línea y aquí es donde la alegoría de la imposibilidad del acercamiento es, desde mi perspectiva, más evidente, más 
nítás nítida-, Enríquez da cuenta de que le fue absolutamente imposible acercarse a la estancia de los Bioy: "es imposible visitarla", consigna, y agrega:

La familia -el nieto mayor de Bioy y Silvina, Florencio Basavilbaso, que a través de un gerenciador se ocupa del campo- no quiere que se acerquen curiosos ni investigadores ni periodistas. A veces el cuidador permite, al menos, avistar la casa desde lejos. Pero el día de la visita no hay suerte (36, énfasis mío).

Enríquez, en consecuencia, se ve obligada a situarse lejos de su biografiada, a avistarla -como a la estancia Rincón Viejo- desde la distancia: esa es, entre otras, una de las razones de su cautela.

Ahora bien, ¿de qué modo aborda Enríquez en La hermana menor la literatura escrita por Silvina Ocampo? Por lo pronto, habría que decir que ese es el terreno donde parece sentirse más cómoda, más suelta, más cerca de su biografiada. Hay una evidente sintonía entre la literatura de Enríquez y la de Ocampo que redunda en cierta facilidad con la que la primera se acerca a los textos de la segunda, en especial a la prosa. En el artículo ya mencionado, Rampersad asegura: "La biografía de un escritor debe de algún modo sugerir una íntima relación con el arte de ese escritor. Una biografía de un escritor debe ser, de alguna manera, algo así como una extensión del mundo de la poesía o de la prosa de ese escritor, o seguramente algo ha fallado" (1992: 17). Esa "extensión" de la que habla Rampersad sólo se advierte en el comienzo de La hermana menor, en esa sugestiva escena de la niña de clase alta subida a un cedro de la casa paterna, "comiendo terrones de azúcar con limón" y esperando la llegada de "sus visitantes favoritos: los mendigos" (13). Pero luego, el libro redunda las más de las veces en un acercamiento más escolar, más periodístico -en el sentido más rutinario del término- y menos creativo, a la escritura de Ocampo. De este modo, La hermana menor resulta una posible aunque muy a menudo escolar puerta de ingreso al universo literario de Ocampo, del que Enríquez da cuenta apuntando, prolija y algo monótonamente, búsquedas, obsesiones, temas recurrentes, procedimientos, etcétera.

Sin embargo, en esa cierta desenvoltura con la que Enríquez aborda la escritura de Ocampo creo hallar una zona de dificultad o de rispidez cuando debe poner en relación esa literatura con la vida de su autora. Es decir, cuando Enríquez debe dar cuenta del par vida-obra, pilar central de toda biografía de escritor. Nuevamente aquí aparece la biógrafa intimidada, amedrentada, cautelosa. En este caso, considero que esa situación proviene del peso que sobre ella ejerce cierto dictum de la teoría literaria (en muchas de sus variantes) que prohíbe leer la obra de un autor en clave biográfica. En este sentido, en la nota publicada por el diario La Nación que mencioné más arriba, Enríquez quiere mostrarse muy consciente de ese dictum al declarar enfáticamente que "No se puede leer la literatura de un autor a la luz de su vida, salvo que sea explícitamente autobiográfica. Cuando se escribe, el autor siempre es otro". No obstante, en La hermana menor, Enríquez señala:

Gran parte de la literatura de Silvina Ocampo parece contenida ahí: en la infancia, en las dependencias de servicio. De ahí parecen venir sus cuentos protagonizados por niños crueles, niños asesinos, niños asesinados, niños suicidas, niños abusados, niños pirómanos, niños perversos, niños que no quieren crecer, niños que nacen viejos, niñas brujas, niñas videntes; sus cuentos protagonizados por peluqueras, por costureras, por institutrices, por adivinas, por jorobados, por perros embalsamados, por planchadoras. Su primer libro de cuentos, Viaje olvidado (1937), es su infancia deformada y recreada por la memoria; Invenciones del recuerdo, su libro póstumo, de 2006, es una autobiografía infantil. No hay período que la fascine más; no hay época que le interese tanto.

¿Por qué Enríquez escribe “parece contenida ahí” y no “está contenida ahí”? ¿Por qué, en el mismo sentido, escribe "de ahí parecen venir sus cuentos" y no "de ahí vienen sus cuentos"? Advierto aquí, en ese uso en función atenuadora del verbo "parecer", esa cautela a la que acabo de referirme: es como si Enríquez estuviera pidiendo perdón por anticipado, como si se estuviera atajando preventivamente por atreverse siquiera a postular una lectura en clave biográfica de la literatura de Ocampo. Por tanto, si bien en algunas pocas oportunidades la biógrafa abandona ese tono prudente y se vuelve más asertiva -por ejemplo, cuando asegura que "En 1949, con Poemas de amor desesperado, inauguró una poesía amorosa que, por ejemplo en 'Sonetos de amor desesperado', configura una ética del amor que es imposible no considerar autobiográfica” (65) o, 
por dar otro ejemplo más, cuando afirma que la protagonista del cuento "El diario de Porfiria Bernal" es un "velado alter ego de Silvina" (118)-, el título de uno de los capítulos finales - Mi vida no tiene nada que ver con lo que escribo", tomado de una entrevista que le realizó Noemí Ulla- está ahí -o al menos esa es mi interpretación- para prevenir al lector sobre lo desacertado que sería incurrir en demasía en una lectura biografista de la obra de Ocampo. ${ }^{7}$

Para concluir: La hermana menor, posiblemente, es un texto que no habría podido tener lugar en un contexto que no fuera el del retorno al autor y al sujeto del que somos testigos desde hace unos años. ${ }^{8}$ Las vidas -y entre ellas las vidas de los escritores- volvieron a interesar y La hermana menor no es sino un emergente más de ese interés, como lo son, cada uno a su modo, Osvaldo Lamborghini, una biografía, de Ricardo Strafacce, Barón Biza, el inmoralista y La amargura metódica. Vida y obra de Ezequiel Martínez Estrada, de Christian Ferrer, o Fogwill, una memoria coral, de Patricio Zunini (todas ellas mencionadas por Lezcano en su nota para La Nación). En estas páginas, no obstante, me interesó detenerme en ciertas cautelas de $L a$ hermana menor -en especial con respecto a su inscripción genérica y al modo como en ella se aborda el par vida y obra- porque en ellas pueden leerse ciertos problemas de la biografía de escritor en la contemporaneidad, ciertos interrogantes que se le plantean inevitablemente a un biógrafo al momento de emprender su labor a no ser que no tema pecar de ingenuo o de anacrónico. ¿El autor ha dejado de desaparecer? Seguramente. Los modos de su retorno, sin embargo, no terminan de delinearse, y acaso no deban hacerlo.

\section{BIBLIOGRAFÍA}

Arfuch, Leonor (2017). "Elaborar la narrativa de una vida es parte de la búsqueda de sentido" (entrevista), en Revista Transas. Recuperado de: http://www.revistatransas.com/2017/03/09/elaborar-la-narrativa-de-unavida-es-parte-de-una-busqueda-de-sentido-entrevista-a-leonor-arfuch/.

Ayala-Dip, Ernesto (2014). "La pequeña Ocampo", El País, suplemento "Babelia”, 5 de septiembre. Recuperado de: http://cultura.elpais.com/cultura/2014/09/03/babelia/1409762503_411030.html

Berlanga, Ángel (2014). “Yo, la menor de todas”, Página/12, suplemento "Radar Libros”, 6 de julio. Recuperado de: http://www.pagina12.com.ar/diario/suplementos/libros/10-5358-2014-07-06.html

Dosse, François (2007). La apuesta biográfica. Escribir una vida, Valencia, PUV.

Edel, Leon (1990). Vidas ajenas. Principia biographica, Buenos Aires, Fondo de Cultura Económica.

Enríquez, Mariana (2014). La hermana menor. Un retrato de Silvina Ocampo, Santiago de Chile, Ediciones Universidad Diego Portales.

Lezcano, Walter (2016). “De Silvina Ocampo a Osvaldo Lamborghini: las mejores biografías de escritores”, La Nación, suplemento "Ideas", 3 de agosto. Recuperado de: http://www.lanacion.com.ar/1924375-vidas-para-leerlas-lasmejores-biografias-de-escritores

Momigliano, Arnaldo (1986). Génesis y desarrollo de la biografía en Grecia, México, Fondo de Cultura Económica.

Premat, Julio (2006). "El autor. Orientación teórica y bibliográfica", en Figures d'auteur, Cahiers de LI.RI.CO, nº 1, pp. 311-317.

Rampersad, Arnold (1992). "Design and Truth in Biography”, en South Central Review, vol. 9, no 2, pp. 1-18.

Zunini, Patricio (2014). "Silvina en la bruma [reportaje a Mariana Enríquez]". Recuperado de: http:// eternacadencia.com.ar/blog/contenidos-originales/entrevistas/item/silvina-en-la-bruma.html

\section{Notas}

1 Además de otros libros, Rampersad (nacido en 1941) es autor de tres biografías: The Life of Langston Hughes (1986 y 1988), Jackie Robinson: A Biography (1997) y Ralph Ellison: A Biography (2007).

2 En un trabajo publicado en este mismo dossier, Antonio Marcos Pereira, acertadamente, denomina a esas biografías "formas canónicas de la biografía". 
3 En este caso, algunas de las definiciones de "perfil” que propone el Diccionario de la RAE ("Contorno de la figura de algo o de alguien" y "Conjunto de rasgos peculiares que caracterizan a alguien o algo") tampoco aportan demasiado para establecer el distingo.

4 Acerca del carácter vulnerable del género, Dosse se refiere a la "indefinición epistemológica" que lo caracteriza: "El género biográfico es una mezcla de erudición, de creatividad literaria y de intuición psicológica” (2007: 60). Una pregunta posible es pensar por qué la escritora Mariana Enríquez, autora de numerosos textos de ficción, no optó por escribir lo que comúnmente se llama biografía novelada. En esta línea, pienso también en ciertas entonaciones de lo biográfico como El loro de Flaubert, de Julian Barnes, o Rimbaud en Java, de Jamie James.

5 Dosse establece que, como género, la biografía se define por una "tensión" entre "la voluntad de reproducir según las reglas de la mímesis" y el "polo imaginativo" (2007: 55) al que ya hice referencia. Al respecto, y en relación con la pregunta que realicé en la nota anterior, otro interrogante es por qué, dadas las condiciones en que debió escribir este texto, Enríquez no se decidió por inclinarse más hacia ese "polo".

6 En este sentido debe leerse la decisión de Enríquez de enunciar mitos y no revelarlos. En la entrevista ya mencionada que le realizó Patricio Zunini, declara: "Y, como no pude acceder a los materiales más reveladores porque los tiene el albacea, no tuve mucho interés en develarlos. Preferí dejar sentado el mito, lo que me parece más interesante porque no es una investigación policial. Me cerraba más que ir desesperadamente detrás de los hechos para saber qué era cierto”. Un problema del texto, creo, es que Enríquez muchas veces confunde el “mito” con el mero lugar común biográfico.

7 La fuerte presencia que en el texto de Enríquez tiene el discurso académico sobre la obra de Ocampo -en especial los trabajos de Noemí Ulla, Adriana Mancini y Judith Podlubne- debe ser leída en el mismo sentido.

8 Acerca de la relación entre el nuevo interés por la subjetividad y su relación con géneros como la biografía y la autobiografía, puede leerse una entrevista reciente a Leonor Arfuch (2017), autora de El espacio biográfico. 